\title{
Frequency of different Groove Patterns on the Occlusal Surface of Mandibular Second Premolars
}

\author{
Muhammad Abul Hasan Ali ${ }^{1}$, Maham Niazi ${ }^{2}$, Sania Saqib ${ }^{3}$, Ahmed Younas ${ }^{4}$, Najeeb Khan 5 \\ ${ }_{1}^{1}$ Post Graduate Resident, Department of Oral Medicine, Islamabad Medical and Dental College \\ ${ }^{2}$ Associate Professor, Department of Oral Biology, Islamabad Medical and Dental College \\ ${ }^{3}$ Assistant Professor, Department of Oral Biology, Islamabad Medical and Dental College \\ ${ }^{4,5}$ Ex-House Surgeons, Islamabad Dental Hospital
}

ABSTRACT

\begin{abstract}
Background: The Mandibular second premolar has commonly three different type traits depending on the occlusal groove patterns. In addition to that they are also recognized on the basis of number of cusps. The objectives of the study were to determine the frequency of different occlusal groove patterns of mandibular second premolars and to acquire base line data for future studies in this population and field of research.
\end{abstract}

Material and Methods: This study was conducted in Islamabad Dental Hospital (IDH), from September 2017 to December 2017. A total of 600 patients (1200 teeth) with fully erupted mandibular second premolars of normal occlusal morphology, in age group of 15 years and above were screened in the Out Patient Department (OPD). Groove patterns on occlusal surfaces and their anatomical variations on both sides i.e. right and left, were observed and noted in a proforma. Data was analyzed using SPSS version 22.

Results: Three different patterns of occlusal grooves $(\mathrm{Y}, \mathrm{U}$ and $\mathrm{H})$ were found in our study population. $\mathrm{Y}$ groove pattern was observed in 364 teeth (30.33\%), $\mathrm{U}$ pattern in 447 teeth $(37.25 \%)$ and $\mathrm{H}$ pattern was noted in $389(32.41 \%)$ teeth. Among males, $\mathrm{U}$ pattern was predominant (43.84\%) followed by $\mathrm{H}$ and then $\mathrm{Y}$ pattern. In females, $\mathrm{H}$ pattern grooves was found mostly $(34.41 \%)$, followed by $Y$ and $U$ pattern.

Conclusion: The most frequent occlusal groove pattern observed in our population was $\mathrm{U}$ followed by $\mathrm{H}$ and $\mathrm{Y}$ type.

Key words: Grooves, Mandibular, Occlusal surface, Premolar

Authors' Contribution: Correspondence:

1. Conception, synthesis, planning of research Maham Niazi

Article info:

and manuscript writing 2,3 'nterpretation,

Email: Maham.niazi@iideas.edu.pk

Received: January 12, 2019

discussion, ${ }^{4,5}$ Active participation in data

Accepted: April 17, 2019

collection and data analysis.

Cite this article. Ali MAH, Niazi M, Saqib S, Younas A, Khan N. Frequency of Different Groove

Patterns on the Occlusal Surface of Mandibular Second Premolars. J Islamabad Med Dental

Funding Source: Nil

Conflict of Interest: Nil

Coll.2019; 8(2):84-87

\section{Introduction}

Human teeth have always been known for morphological variations in both crown and the root structures. ${ }^{1}$ The coronal morphological variations can be in the form of extra cusp/cusps, missing cusp/cusps or variations in groove patterns. ${ }^{2}$ These structural variations in teeth are the part of dental anthropological system and should be determined in different populations and/or races, as it can be of great help in identifying the age, gender or race of a deceased individual or cultural practices, habits or anomalies prevalent in a population. ${ }^{1}$ The developmental, structural and restorative dental work accounts for ante mortem dental records, which can be of significant importance for forensic dentists in identifying victims in mass disasters, like for 2001 world trade center attack and 2004 Phuket tsunami. ${ }^{1,3}$

The fifth tooth from midline in both lower quadrants is mandibular second premolar. It erupts at the age of 11-12 years when its predecessor tooth, deciduous second molar sheds. ${ }^{2}$ This tooth, mesially, has a contact with the mandibular first premolar and on the distal aspect with the 
permanent mandibular first molar. ${ }^{4}$ The second premolar has generally a larger crown, and slightly wider and longer root than the first premolar.5,6 The function of second premolar is to assist molars in mastication as opposed to the first premolar which functions much like the canine. ${ }^{4}$

The mandibular second premolar can be observed as either a bicuspid or a tricuspid but variations in its occlusal groove patterns may exist. There are three different observed patterns of occlusal grooves. $Y$ shape pattern is related mostly to three cusps type variety while $\mathrm{U}$ and $\mathrm{H}$ shape patterns are associated with bicuspid premolars. ${ }^{4}$ If the central groove is a horizontal line between the mesial and distal pits, this pattern is known as $\mathrm{H}$ type but if it is crescent shaped it is a $\mathrm{U}$ type occlusal groove pattern. ${ }^{4}$

Clinically, the rare discrepancy in the leeway space because of difference in mesio-distal width of two and three cusps type can lead to prediction of slight crowding or spacing and can be helpful in orthodontic treatment planning. ${ }^{6}$ Three-cups type can be the tooth of choice in extraction cases, as it will give more space for proper alignment. ${ }^{7}$ On the other hand where mild crowding is present or where space is remaining at the end of the treatment, the two-cusp type can undergo a buildup to close the extraction space. ${ }^{7,8}$ The coronal morphology of tooth sculpts an outline of the radicular morphology including the configuration and the number of root canals. Anomalous coronal morphological features like supplemental cusps, tubercles, deep occlusal grooves or altered mesio-distal dimension could be complemented by anomalous endodontic morphology which compounds the struggle for clinicians. Updated knowledge and thorough clinical examination can aid an endodontist in quality and satisfying practice.8,9 Dental morphology including occlusal groove patterns, missing teeth, dental restorations, crowding or wear pattern of teeth and other unusual dental variances give every individual a distinctive identity. The records of these characters can help in identification of a deceased individual and so are employed in the field of dental anthropology and forensic dentistry. ${ }^{1}$ Studies among different populations showed that $U /$ crescent shaped occlusal grooves pattern is predominant in South Indian $(45.2 \%)^{10}$ and Pakistani
$(54 \%)^{7}$ subjects while Singaporean Chinese population exhibited H-shaped pattern (75.9\%). ${ }^{11}$

The purpose of the present study was to investigate the prevalence of various groove patterns seen on occlusal surface of mandibular second premolars in patients reporting to Islamabad Dental Hospital, so we could gather a baseline data of this variation in the said population.

\section{Material and Methods}

This descriptive cross-sectional study was conducted in Islamabad Dental Hospital, Bhara kahu with the permission of Institutional Review board (IRB) and written informed consent of the participants. A total of 600 patients of age 15 years and above regardless of gender were selected for the study. Fully erupted mandibular second premolars with normal morphology were included and any lower second premolar with restoration, decay, trauma or fracture were excluded from the study. All the participants were examined in the outpatient department (OPD), readings were noted down in a proforma and data was analyzed using SPSS version 22.0

\section{Results}

A total of 1200 teeth from 600 subjects were examined. Among them 340 (56.7\%) were females and 260 (43.3\%) were males. Most frequent occlusal groove pattern observed was $U$ shaped in 447 teeth $(37.25 \%)$ followed by $\mathrm{H}$ in 389 teeth (32.41\%) and $\mathrm{Y}$ in 364 teeth (30.33\%). (Table I) Among males, the most predominant groove pattern was U/crescent shaped on both left (46.53\%) and right $(41.15 \%)$ quadrants followed by $\mathrm{H}$ and then $\mathrm{Y}$ pattern.

\begin{tabular}{|l|c|c|c|}
\hline \multicolumn{4}{|c|}{ Table I: Distribution of different occlusal groove patterns in } \\
the study population \\
\hline $\begin{array}{l}\text { Groove } \\
\text { pattern }\end{array}$ & $\begin{array}{c}\text { Total Number of } \\
\text { teeth } \\
\mathbf{n}(\%)\end{array}$ & Right side & Left side \\
\hline U shaped & $447(37.25 \%)$ & 217 & 230 \\
\hline H shaped & $389(32.42 \%)$ & 199 & 190 \\
\hline Y shaped & $364(30.33 \%)$ & 184 & 180 \\
\hline Total & 1200 & 600 & 600 \\
\hline
\end{tabular}


In female participants the most frequent pattern was $\mathrm{H}$ type both on left $(34.70 \%)$ and right $(34.11 \%)$ sides, followed by $Y$ and U pattern. (Table II) (Graphs I \& II).

\begin{tabular}{|c|c|c|c|c|}
\hline \multicolumn{5}{|c|}{$\begin{array}{c}\text { Table II: Gender-wise distribution of different occlusal groove } \\
\text { patterns }\end{array}$} \\
\hline Gender & $\begin{array}{c}\mathrm{U} \\
\text { pattern }\end{array}$ & $\begin{array}{c}\mathrm{H} \\
\text { pattern }\end{array}$ & $\begin{array}{c}\mathrm{Y} \\
\text { pattern }\end{array}$ & $\begin{array}{l}\text { Total Number of } \\
\text { teeth } \\
n(\%)\end{array}$ \\
\hline Female & 219 & 234 & 227 & $680(56.7)$ \\
\hline Male & 228 & 155 & 137 & $520(43.3)$ \\
\hline Total & 447 & 389 & 364 & 1200 \\
\hline
\end{tabular}
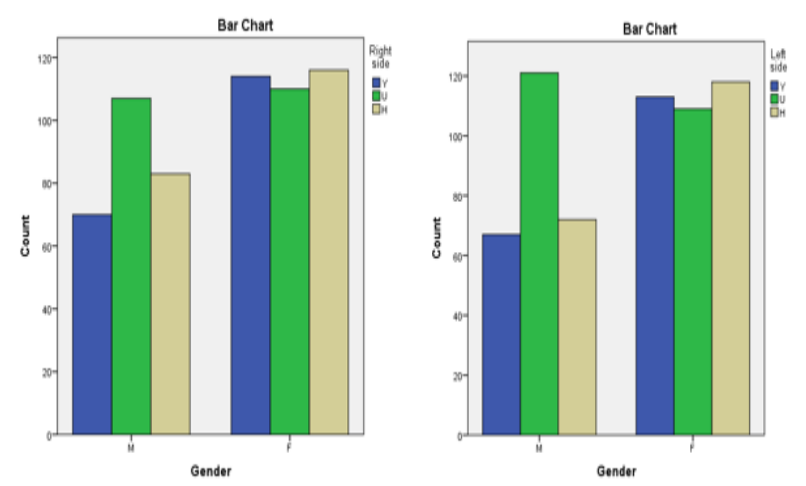

Graphs I \& II: Gender-wise distribution of occlusal grooves in right and left quadrant

\section{Discussion}

In different populations, the mandibular second premolar exists with different morphological features, so in order to clinically identify and differentiate its variants, a complete knowledge regarding its type traits is essential to the task at hand. ${ }^{9}$ Clinically it has two types, bicuspids and tricuspids. The tricuspid type is overall larger than the usual bicuspid premolar and is also known as a mini molar or the transitional tooth with some of its features resembling a canine, for instance a single root or having multiple cusps such as those of molars. On the basis of occlusal morphology/anatomy it has further three types because of the configuration of primary grooves. ${ }^{7}$

In the current study, the most frequently observed occlusal groove pattern was $\mathrm{U} / \mathrm{crescent}$ shaped i.e. $37.25 \%$ followed by $\mathrm{H}(32.41 \%)$ and $\mathrm{Y}$ shaped grooves (30.33\%). Crescent/U shaped grooves were predominant in bicuspid type as compared to the $\mathrm{H}$ pattern which is more frequent in Chinese and Europeans and is consistent with the work done by Ahmed and colleagues who conducted the study in school going children in Lahore $^{7}$ and Sunil and Gopakumar who studied mandibular premolars in Kerala population. ${ }^{10}$ However our results are contrary to the findings of Hong Yoo and colleagues who reported the $Y$ pattern to be predominant in the Korean population. ${ }^{12}$

Gender predilection is different for groove patterns; in females' $H$ shaped pattern was most frequent $(34.41 \%)$ as compared to males who mostly showed U/crescent grooves $(43.84 \%)$. But overall, the most pronounced pattern in this population was $\mathrm{U}$ shaped occlusal groove pattern, similar to what was observed by Mosharraf and Hajian in Iran, where it was found to be $44 \% .{ }^{13}$ The frequency observed in our study is analogous to the study by Ahmed et al., who also reported the same distribution of occlusal grooves pattern generally as well as for both genders independently. ${ }^{7}$ Loh in a study on Singaporean Chinese population demonstrated that $66.3 \%$ exhibited bicuspid variety whereas $25.4 \%$ showed tricuspid premolars. ${ }^{11}$ In a local study conducted by Ahmed et al. ${ }^{7}$ in different schools of Lahore, Pakistan the frequency of 2 -cusps and 3-cusps variety was found to be $37.5 \%$ and $62.4 \%$ respectively, which is contrary to the figures presented by Bath Balogh and Fehrenbach, ${ }^{14}$ who reported it to be $45 \%$ (2-cusp) and $55 \%$ (3- cusp) individually.

\section{Conclusion}

Dental morphological studies are important for anthropological research, forensic dentistry and clinical sciences. The results of our study can contribute to all of the aforementioned. Further studies based on these baseline statistics, involving larger population are expected to assess gender preference and incidence more proficiently. 


\section{References}

1. Krishan K, Kanchan T, Garg AK. Dental evidence in forensic identification- an overview, methodology and present status. Open Dent J. 2015; 9: 250-6. doi: 10.2174/1874210601509010250

2. Coro JC, Velasquez RL, Coro IM, Wheeler TT, McGorray SP. Relationship of maxillary 3-dimensional posterior occlusal plane to mandibular spatial position and morphology. Am J Orthod Dentofacial Orthop. 2016; 150(1):140-52. doi: 10.1016/j.ajodo.2015.12.020.

3. Kolude B, Adeyemi BF, Taiwo JO, Sigbeku OF, Eze ann UO. The role of forensic dentist following mass disaster. Ib Postgrad Med. 2010;8(2):111-7. PMID: 25161478

4. Fuller, JL. Denehy GE, Schulein TM. Concise dental anatomy and morphology. 4th ed. lowa, University of lowa College of Dentistry. 2013:86-98.

5. Gunduz K, Avsever H, Orhan K, Canitezer G, Acikgoz A, $\mathrm{Oz} \mathrm{U}$. A multi-center evaluation of multiple supernumerary premolar prevalence. Aust Orthod J. 2015;31(2):149-56. PMID: 26999887

6. Allen TR, Trojan TM, Harris EF. Evidence favoring a secular reduction in mandibular leeway space. The Angle Orthodontist. 2017;87(4):576-82. doi: 10.2319/091416688.1

7. Ahmed A, Iqbal N, Baig MZ. Frequency of type traits of mandibular second premolars a study. PODJ. 2016;36(3):430-2.
8. Habib AA, Kalaji MN, J. Al saysd T, Al jawfi KA. Root canal configurations of the first and second mandibular premolars in the population of north Syria. Journal of Taibah University Medical Sciences, 2015;10(4):391-5. doi: 10.1016/j.jtumed.2015.02.011

9. Farooq J, Ahmed I, Gul-e-Erum, Iqbal SN. Relationship between tooth dimensions and malocclusion. J Pak Med Assoc. 2014; 64(6): 670-4. PMID: 25252487

10. Sunil $S$ and Gopakumar D. Prevalence of the two variants of mandibular second premolars in Kerala population. Int. J Odontostomat. 2012; 6(3): 375-7.

11. Loh HS. Coronal morphology of the mandibular second premolar in the Singaporean Chinese. Aust Dent J. 1993; 38(4): 283-86. PMID: 8216036

12. Yoo HI, Park HY, Kim SH. Occlusal Surface Analysis of Mandibular Premolars in Koreans. Korean J Phys Anthropol. $2015.28(3): 145-153 . \quad$ doi: 10.11637/kjpa.2015.28.3.145

13. Mosharraf R and Hajian F. Occlusal morphology of the mandibular first and second premolars in Iranian adolescents. J Dent Anthropol. 2004;13(5):94-6.

14. Bath-Balogh M, Fehrenbach MJ. Occlusion in Dental embryology, Histology, and Anatomy. 3rd ed. Philadelphia: WB Saunders. 2011: 198-205. 